$\stackrel{W}{=}$

Global journals Inc.

है

\title{
Neglected Trans-Scaphoid Volar Perilunate Dislocation with Post-Operative Complex Regional Pain Syndrome: A Case Report
}

\author{
By Apoorv Sehgal, Pratyush Shahi, Aarushi Sudan, Sushil Kamal, \\ Umesh Meena \& Debasish Meher
}

Abstract- We present the case report of a 30-year-old male who fell from a height of 15 feet on his palmar-flexed right wrist and came to us 1 month after the injury. He had a swollen, stiff wrist with painful movements and no neurovascular deficit. X-rays showed a trans-scaphoid volar perilunate dislocation. We used the volar approach for open reduction and internal fixation with a headless screw for scaphoid fracture and scapho-lunate and capito-lunate K-wires for intercarpal instability. The wrist was immobilised in a below-elbow POP slab for 6 weeks after which the Kwires were removed. The patient unfortunately developed complex regional pain syndrome (CRPS), which can be attributed to his late presentation after the injury. Active and passive range of motion exercises and contrast bath were initiated and he was kept on low dose amitriptyline. Gradually CRPS resolved and at 6-month follow-up, the patient had a wrist dorsiflexion of $30^{\circ}$ and palmar-flexion of $45^{\circ}$.

GJMR-H Classification: NLMC Code: WE 175

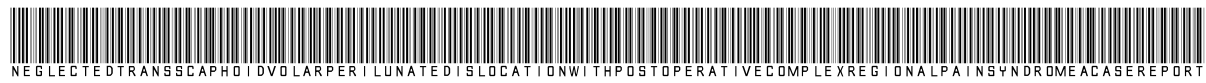

Strictly as per the compliance and regulations of:

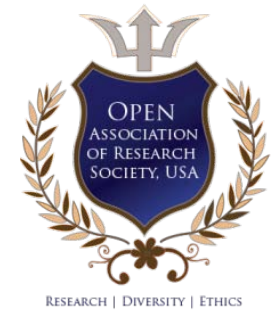

(c) 2020. Apoorv Sehgal, Pratyush Shahi, Aarushi Sudan, Sushil Kamal, Umesh Meena \& Debasish Meher. This is a research/review paper, distributed under the terms of the Creative Commons Attribution-Noncommercial 3.0 Unported License http://creativecommons.org/licenses/by-nc/3.0/), permitting all non-commercial use, distribution, and reproduction in any medium, provided the original work is properly cited. 


\title{
Neglected Trans-Scaphoid Volar Perilunate Dislocation with Post-Operative Complex Regional Pain Syndrome: A Case Report
}

\author{
Apoorv Sehgal ${ }^{\alpha}$, Pratyush Shahi $^{\sigma}$, Aarushi Sudan $^{\circ}$, Sushil Kamal $^{\omega}$, Umesh Meena $^{\sharp}$ \& Debasish Meher ${ }^{\S}$
}

Abstract- We present the case report of a 30 -year-old male who fell from a height of 15 feet on his palmar-flexed right wrist and came to us 1 month after the injury. He had a swollen, stiff wrist with painful movements and no neurovascular deficit. Xrays showed a trans-scaphoid volar perilunate dislocation. We used the volar approach for open reduction and internal fixation with a headless screw for scaphoid fracture and scapho-lunate and capito-lunate K-wires for intercarpal instability. The wrist was immobilised in a below-elbow POP slab for 6 weeks after which the K-wires were removed. The patient unfortunately developed complex regional pain syndrome (CRPS), which can be attributed to his late presentation after the injury. Active and passive range of motion exercises and contrast bath were initiated and he was kept on low dose amitriptyline. Gradually CRPS resolved and at 6-month follow-up, the patient had a wrist dorsiflexion of $30^{\circ}$ and palmar-flexion of $45^{\circ}$.

\section{INTRODUCTION}

V olar perilunate dislocation (VPLD) is a rare injury accounting for about $3 \%$ of perilunate dislocations which comprise of less than $10 \%$ of all wrist injuries. ${ }^{1}$ It generally occurs due to high-energy trauma and is frequently missed. Open reduction and internal fixation is the ideal treatment due to variable results with closed reduction. ${ }^{2}$ Patients presenting late are particularly difficult to manage due to soft tissue contractures and increased chances of 1) avascular necrosis of scaphoid and lunate, 2) tractional injury to neurovascular structures, 3) wrist stiffness, and 4) complex regional pain syndrome (CRPS). ${ }^{3}$

We, through this case report, aim to highlight the problems faced in managing neglected VPLDs and importance of prompt restoration of intercarpal alignment in such injuries to prevent complications. We also state that early recognition and treatment improves patient outcomes in CRPS.

\section{il. Case Presentation}

A 30-year-old man presented to us with pain in the right wrist and restricted movements. He had fell down from a height of around 15 feet on his palmarflexed wrist a month back. He took the primary treatment from an osteopath where some kind of bandaging was done. He came to us when his symptoms hadn't subsided one month after the injury. On examination, there was diffuse tenderness and swelling over the right wrist with restriction of movements. The overlying skin was normal. There was no weakness or paresthesia in the right hand. X-rays suggested a trans-scaphoid volar perilunate dislocation. (Figure 1) 

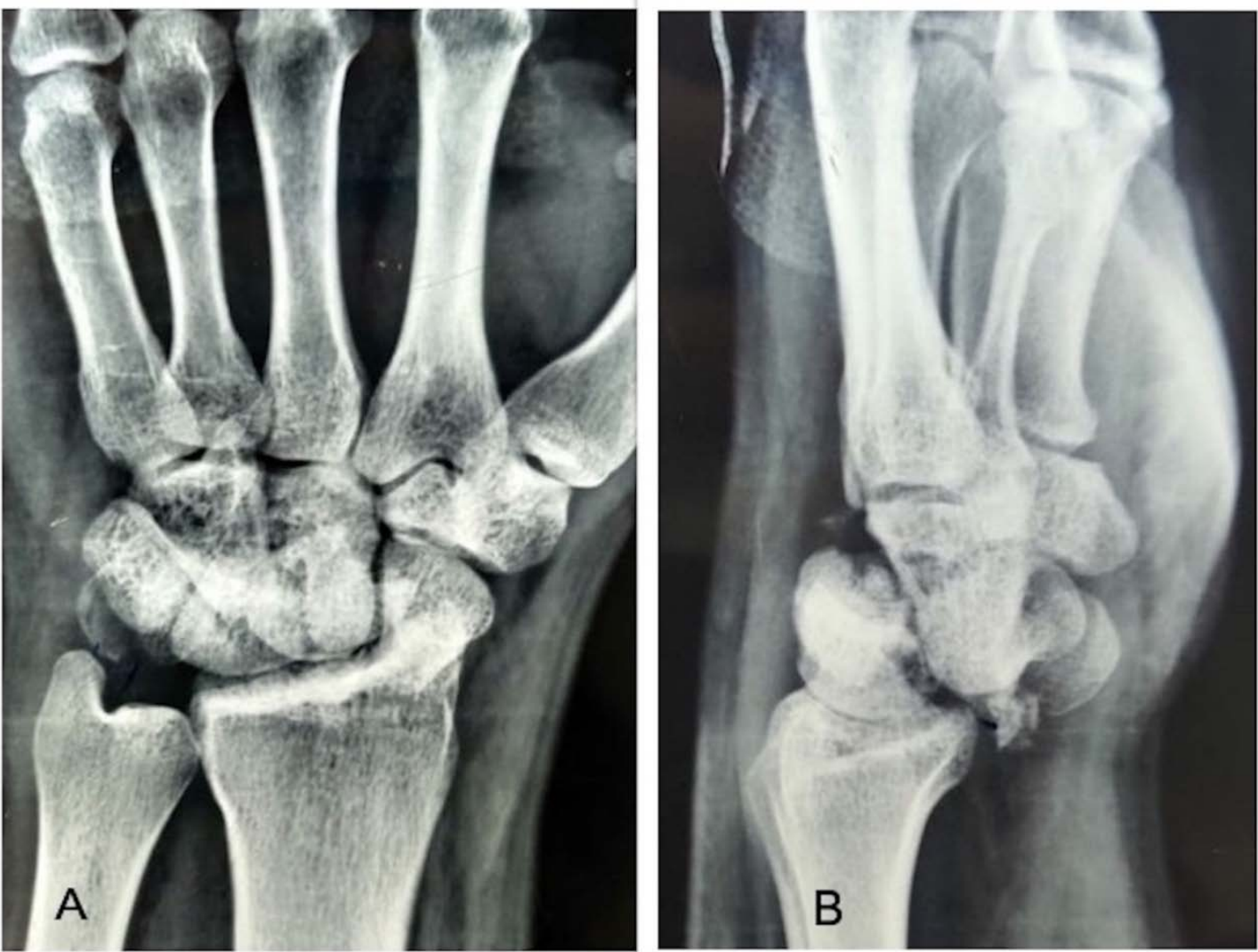

Figure 1: Shows (A) disruption of Gilula's lines, crowding of carpals and fracture of the waist of scaphoid on the anteroposterior view, and (B) trans-scaphoid volar perilunate dislocation on the lateral view

After taking an informed consent, we took the patient to the operating table. We used the volar approach to the scaphoid. Intra-operatively, we found a comminuted fracture of the scaphoid and gross intercarpal instability. We did open reduction and internal fixation with a headless screw for scaphoid fracture and scapho-lunate and capito-lunate K-wires for intercarpal instability.

The patient was kept on a below-elbow plaster slab for 6 weeks, after which it was removed along with the K-wires and range of motion exercises were started. Unfortunately, the patient developed complex regional pain syndrome (CRPS) at this point, which was suggested by his complaints of severe burning pain and abnormally increased sweating in the affected area. Xrays showed severe patchy osteopenia around the wrist. Active and passive range of motion exercises and contrast bath were initiated and he was kept on low dose amitriptyline. Gradually CRPS resolved and at 6month follow-up, the patient had a wrist dorsiflexion of $30^{\circ}$ and palmar-flexion of $45^{\circ}$. (Figure 2) 

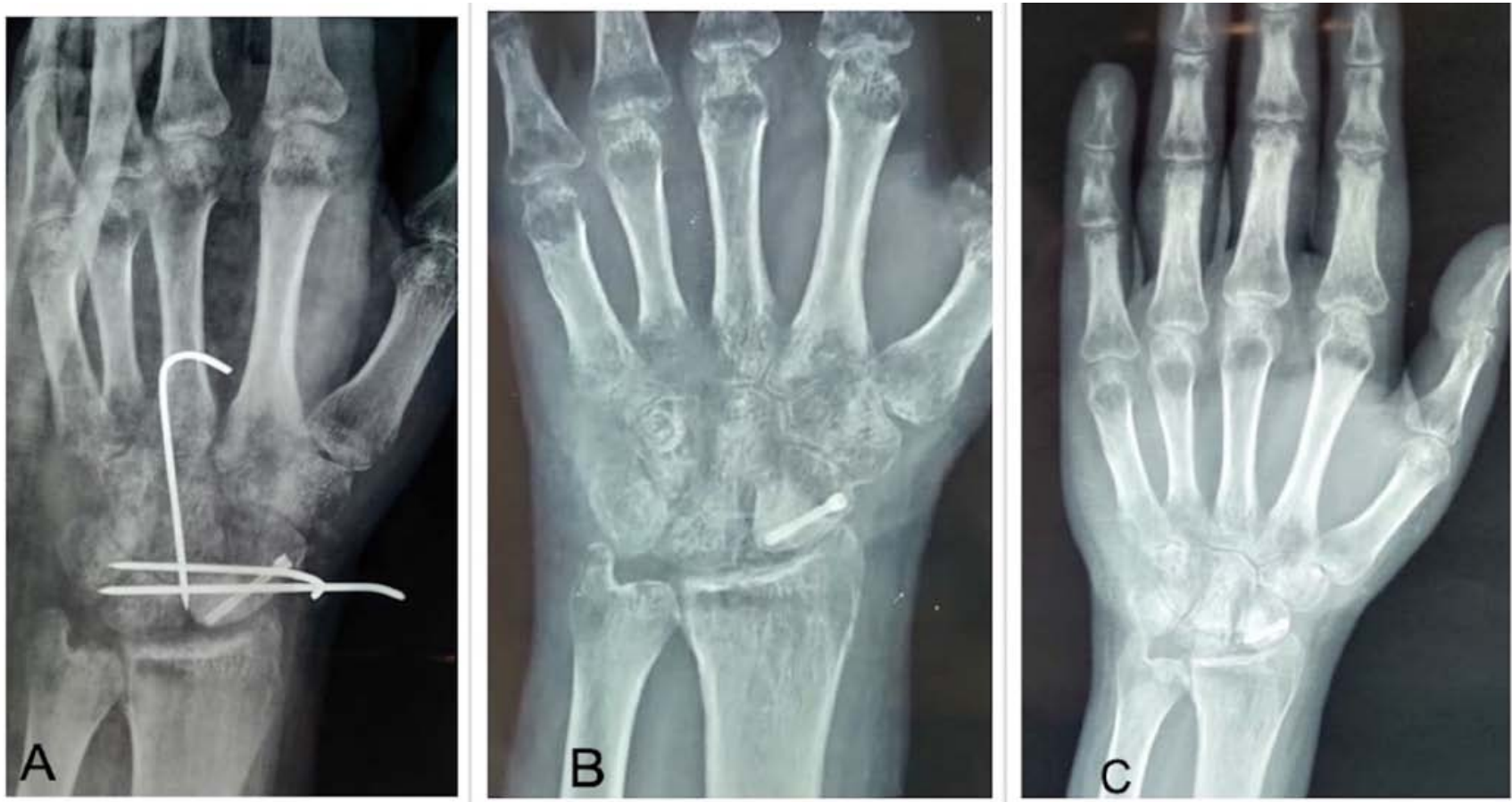

Figure 2: Shows X-rays (A) at 6 weeks and (B) upon K-wire removal depicting severe patchy osteopenia suggestive of complex regional pain syndrome (CRPS); (C) at 4 months with partial resolution of CRPS

\section{Discussion}

Perilunate dislocation comprises volar or dorsal transalation of the carpus secondary to ligamentous or bony disruption around the lunate. This was explained by Johnson as greater arc (associated with a fracture around lunate) and lesser arc (pure ligamentous disruption around lunate) injuries. ${ }^{4}$

Trans-scaphoid volar perilunate dislocation (VPLD) is an extremely rare injury, generally caused by a fall on palmar-flexed and ulnar-deviated wrist. $^{5}$ It is frequently missed and hence, can be neglected. Patients can present with persistent pain and stiffness of the wrist joint with signs of median nerve compression.

Prompt restoration of intercarpal alignment is necessary to prevent complications like median nerve injury, carpal instability, complex regional pain syndrome, avascular necrosis of lunate and scaphoid, and secondary osteoarthritis. ${ }^{6}$ The literature suggests that an open reduction is necessary and can be done till 2 months after the injury. ${ }^{7}$ In patients where open reduction is not successful or those presenting after 2 months, a reconstructive or salvage procedure is generally required. ${ }^{3}$

Patients presenting late with VPLDs have more chances of developing complex regional pain syndrome (CRPS) in the post-operative period. CRPS occurs due to central and peripheral nociceptive sensitisation, altered sympathetic function, inflammatory and immune related factors, brain changes, and psychological factors. ${ }^{8}$ It is characterised by excessive burning pain, swelling, altered sweating pattern and warm or cold skin. Diagnosis is solely clinical. Early recognition and treatment is necessary. Various treatment modalities like drugs (corticosteroids, anti-convulsants, analgesic antidepressants), ganglion blocks, spinal cord stimulation and physical therapy have been documented. ${ }^{9}$

\section{References Références Referencias}

1. Youssef B, Deshmukh SC. Volar perilunate dislocation: a case report and reviewof the literature. Open Orthop J. 2008 Apr 11; 2:57-8.

2. Adkison JW, Chapman MW. Treatment of acute lunate and perilunate dislocations. Clin Orthop Relat Res 1982; 164:199-207.

3. Lal $H$, Jangira $V$, Kakran R, Mittal D. Two stage procedure for neglected transscaphoid perilunate dislocation. Indian J Orthop 2012;46:351-5.

4. Johnson RP. The acutely injured wrist and its residuals. Clin Orthop Relat Res 1980;(149):33-44.

5. Kammano M, Honda Y, Kazuki K. Palmar lunate transscaphoid fracture dislocation caused by a palmar flexion injury. J Orthop Trauma 2001; 15:225-7.

6. Howard FM, Dell PC. The unreduced carpal dislocation. A method of treatment. Clin Orthop Relat Res. 1986 Jan;(202):112-6.

7. Inoue G, Shinova K. Late treatment of unreduced perilunate dislocation. J Hand Surg Br 1999; 24:2215.Bruehl S.

8. An Update on the Pathophysiology of Complex Regional Pain Syndrome. Anesthesiology 2010; 113(3):713-725.

9. Bruehl S. Complex regional pain syndrome. BMJ. 2015 Jul 29; 351:h2730. 